\title{
Article \\ Convergent and Discriminant Validity of the Barthel Index and the EQ-5D-3L When Used on Older People in a Rehabilitation Setting
}

\author{
Billingsley Kaambwa ${ }^{1, *}$, Norma B. Bulamu ${ }^{1}$, Christine Mpundu-Kaambwa ${ }^{2}$ and Raymond Oppong ${ }^{3}$ \\ 1 Health Economics, College of Medicine and Public Health, Bedford Park Campus, Flinders University, Sturt \\ Road, Bedford Park 5042, Australia; norma.bulamu@flinders.edu.au \\ 2 Health and Social Care Economics Group, College of Nursing and Health Sciences, Bedford Park Campus, \\ Flinders University, Sturt Road, Bedford Park 5042, Australia; christine.mpundu-kaambwa@flinders.edu.au \\ 3 Health Economics Unit, Institute of Applied Health Research, University of Birmingham, \\ Birmingham B15 2TT, UK; r.a.oppong@bham.ac.uk \\ * Correspondence: billingsley.kaambwa@flinders.edu.au; Tel.: +61-8-8201-5377
}

check for updates

Citation: Kaambwa, B.; Bulamu, N.B.; Mpundu-Kaambwa, C.; Oppong, R. Convergent and Discriminant Validity of the Barthel Index and the EQ-5D-3L When Used on Older People in a Rehabilitation Setting. Int. J. Environ. Res. Public Health 2021, 18, 10314. https:/ / doi.org/10.3390/ijerph181910314

Academic Editors: Abdulgafoor M. Bachani, Jagnoor Jagnoor,

Margaret Peden and Pedro R. Olivares

Received: 20 July 2021

Accepted: 26 September 2021

Published: 30 September 2021

Publisher's Note: MDPI stays neutral with regard to jurisdictional claims in published maps and institutional affiliations.

Copyright: (c) 2021 by the authors. Licensee MDPI, Basel, Switzerland. This article is an open access article distributed under the terms and conditions of the Creative Commons Attribution (CC BY) license (https:/ / creativecommons.org/licenses/by/ $4.0 /)$.
Abstract: This study compares the empirical performance of a commonly used functional-status measure, the Barthel Index (BI), to that of a widely used generic preference-based instrument, the EuroQoL-5-Dimensions 3 Level (EQ-5D-3L), in older people. Data from older people receiving rehabilitation services were used to test the validity of the BI and EQ-5D-3L. Convergent validity was investigated using Spearman's correlation, exploratory factor analysis (EFA), scatter plots, Krippendorff's alpha and modified Bland-Altman plots. Discriminant validity was examined using Kruskal Wallis tests, ceiling effects and EFA. A total of 1690 participants were included in the analysis. The BI total and EQ-5D-3L utility scores showed moderate correlation ( $\mathrm{r}=0.51$; Krippendorff's alpha $=0.52$. Kendall's Tau-B correlations between BI items and EQ-5D-3L dimensions measuring the same construct were weak to moderate $(0.05 \leq$ absolute $r \leq 0.54)$. In the EFA, some BI items cross-loaded onto the same factors as EQ-5D-3L dimensions, suggesting that the instruments were interrelated. The BI, however, focuses more on physical functioning, while the EQ-5D-3L measures broader wellbeing concepts. Both instruments showed good discriminant validity and would therefore be equally valuable for measuring subgroup differences. Researchers should consider using the $\mathrm{BI}$ in rehabilitation to capture more physical functioning-specific constructs not measured by the EQ-5D-3L.

Keywords: Barthel Index; ED-5D-3L; construct validity; discriminant validity; factor analysis; preference-based

\section{Introduction}

Health-related quality of life (HRQoL) and functional status are interrelated concepts that reflect important outcomes for older people receiving rehabilitation interventions. HRQoL indicates a person's overall health status applicable in different contexts, including clinical studies, health care economic evaluations and population health surveys [1]. On the other hand, functional status and preventing functional decline, in particular, is seen as one of the prime objectives of health care for older people during rehabilitation [2], with a reduction in physical function linked to loss of independence, the need for hospital and long-term nursing-home care, premature death and quality of life decline [3-6]. The World Health Organisation defines rehabilitation as "a set of interventions designed to optimize functioning and reduce disability in individuals with health conditions in interaction with their environment" [7]. Functional status is critical when assessing the effectiveness of rehabilitation interventions as such interventions are organized and provided to ensure attainment of optimal functional improvement [8]. Therefore, the assessment of an individual's functional status is central to the process of rehabilitation [9]. Despite widespread 
agreement that assessing functional status in older persons in rehabilitation is essential [10], the ideal method and preferred instruments for measuring health status, with a particular focus on functioning, is still uncertain. Several health status measures have been used in the rehabilitation of older people. These measures could be generic, such as the EuroQol 5 dimensions 3 level (EQ-5D-3L), or function-specific, such as the Barthel Index (BI) [11]. An attraction of the EQ-5D-3L is that responses to this instrument facilitate the calculation of quality adjusted life years (QALYs) required for conducting cost-utility analysis (CUA), a type of economic evaluation. It is the instrument of choice for performing CUA in some countries such as the UK [12]. Two recent systematic reviews $[13,14]$ reported that it was one of the most widely used HRQoL instruments in economic evaluations of services for older people. An argument against using generic HRQoL instruments such as the EQ-5D-3L is that they can be insensitive and fail to adequately capture essential aspects of health status such as functioning [15]. When the goal is to measure functional status, function-specific instruments such as the BI are seen to be more sensitive [16]. The BI was initially developed to assess disability in patients with neuromuscular and musculoskeletal conditions who were receiving inpatient rehabilitation [11]. It is, however, now recommended for use in the routine assessment of older people by bodies such as the Royal College of Physicians and the British Geriatrics Society [17].

When considering health status measures for potential use in economic evaluation within rehabilitation research targeted at older people (where functional status is a major focus), it is unclear how the BI performs compared to the EQ-5D-3L in terms of construct validity. As the BI has been recommended as a proxy for HRQoL in the literature [18], evidence of a strong correlation between the BI and EQ-5D-3L and comparable or better discriminant validity would provide further evidence of the suitability of using the former for economic evaluations conducted within this population. Using data from a study that evaluated intermediate care services in the UK, this study assessed the convergent and divergent validity of the BI when compared against the EQ-5D-3L. Intermediate care comprises services, including rehabilitation, targeted at preventing admission to acute care or long-term care and aid discharge from hospital for older people in the UK [19]. Whereas the BI has been previously compared to the EQ-5D-3L in stroke patients [20], no simultaneous head-to-head comparison between the BI and the EQ-5D-3L has been performed in a more generic population of older people, as far as we are aware. Therefore, the results of this study will help inform decisions concerning the appropriateness of applying the BI within rehabilitation research focused on older people.

\section{Materials and Methods}

\subsection{Study Design and Recruitment}

This work is based on data collected from a national evaluation of intermediate care services for older people in the UK. Five anonymous primary care trusts (PCTs) were selected as case studies to represent intermediate care rehabilitation settings. A total of 2253 intermediate care participants were recruited from the five primary care trusts chosen to represent 'whole systems' (an area with a specific geographical boundary) of intermediate care [19,21]. By studying 'whole systems' instead of individual service models, we aimed to achieve a more detailed understanding of the implementation of intermediate care. The sites were included in the evaluation if they fulfilled the following criteria:

- A range of intermediate care services operational for at least 2-3 years.

- Reasonable throughput into the intermediate care system (at least 1000 cases per annum).

- A mix of urban and rural sites.

- Senior management support for the collection of routine data by services themselves.

- Clinical and managerial support for participation in the national evaluation.

Data were obtained from these clients at baseline and 12 months using a study proforma that included EQ-5D-3L and BI questionnaires. Other information collected included data on age, gender, living arrangements and type of rehabilitation services required 
(Table 1). In addition, whereas the EQ-5D-3L and BI questionnaires were completed by staff with or on behalf of their patients, only responses obtained using the former approach were included in this study for the sake of consistency in data collection methods. This study focuses only on respondents who received rehabilitation services and had complete data on both the BI and EQ-5D-3L at baseline. All participants provided written informed consent before their inclusion in the study. The Trent Multicentre Research Ethics Committee approved the study.

Table 1. Classifying EQ-5D-3L and Barthel Index dimensions according to the International Classification of Functioning, Disability and Health (ICF) classifications ${ }^{\mathrm{a}}$.

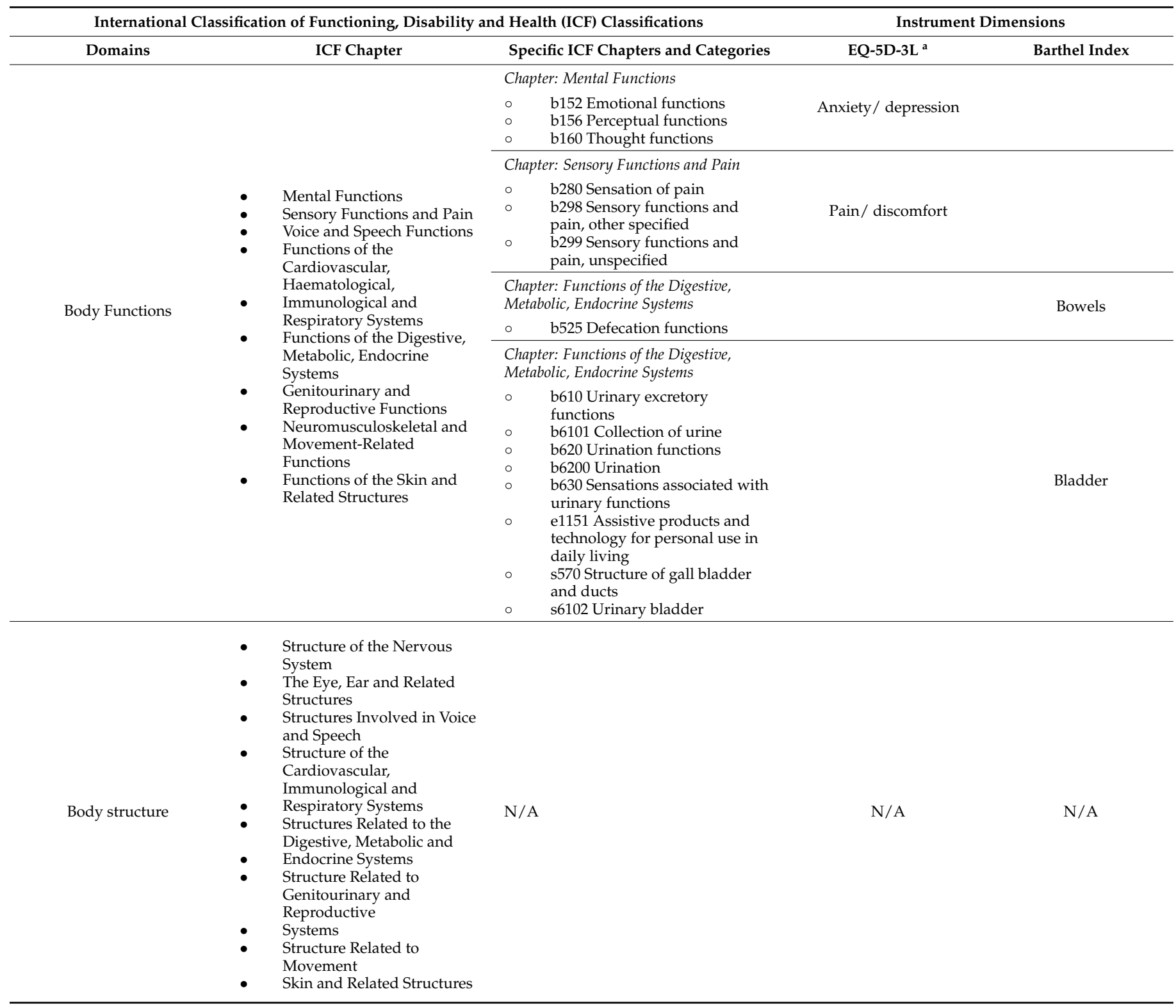


Table 1. Cont.

\begin{tabular}{|c|c|c|c|c|}
\hline \multicolumn{3}{|c|}{ International Classification of Functioning, Disability and Health (ICF) Classifications } & \multicolumn{2}{|c|}{ Instrument Dimensions } \\
\hline Domains & ICF Chapter & Specific ICF Chapters and Categories & EQ-5D-3L ${ }^{a}$ & Barthel Index \\
\hline \multirow{9}{*}{ Activities and Participation } & \multirow{9}{*}{$\begin{array}{ll}\text { - } & \text { Learning and Applying } \\
\text { - } & \text { Knowledge } \\
\text { - } & \text { Comeral Tasks and Demands } \\
\text { - } & \text { Mobility } \\
\text { - } & \text { Self-Care } \\
\text { - } & \text { Interpersonentic Life } \\
\text { - } & \text { and Relationships } \\
\text { - Comor Life Areas } \\
\quad \text { Civic Life }\end{array}$} & Chapter: Mobility & & \\
\hline & & $\begin{array}{ll}\circ & \mathrm{d} 410-\mathrm{d} 429 \text { Changing and } \\
& \text { maintaining body position } \\
\mathrm{d} 450-\mathrm{d} 469 \text { Walking and moving } \\
\circ & \mathrm{d} 498 \text { Mobility, other specified } \\
\circ & \mathrm{d} 499 \text { Mobility, unspecified }\end{array}$ & Mobility & $\begin{array}{l}\text { Mobility } \\
\text { Stairs } \\
\text { Transfer }\end{array}$ \\
\hline & & $\begin{array}{ll}\text { Chapter: Self-Care } \\
\circ & \text { d510 Washing oneself } \\
\circ & \text { d520 Caring for body parts } \\
\circ & \text { d530 Toileting } \\
\circ & \text { d540 Dressing } \\
\circ & \text { d550 Eating } \\
\circ & \text { d560 Drinking } \\
\circ & \text { d570 Looking after one's health } \\
\circ & \text { d598 Self-care, other specified } \\
\circ & \text { d599 Self-care, unspecified }\end{array}$ & Self-care & $\begin{array}{l}\text { Bathing } \\
\text { Grooming Feeding } \\
\text { Dressing Toilet use }\end{array}$ \\
\hline & & 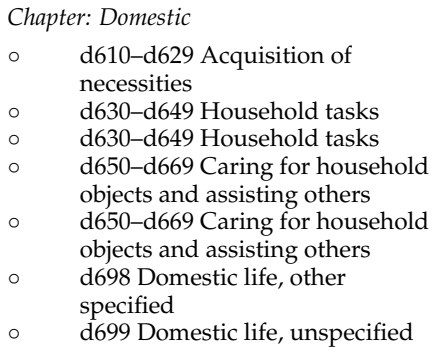 & Usual activities & \\
\hline & & $\begin{array}{l}\text { Chapter: Interpersonal Interactions and } \\
\text { Relationships }\end{array}$ & & \\
\hline & & $\begin{array}{ll}\circ & \mathrm{d} 710-\mathrm{d} 729 \text { General } \\
& \text { interpersonal interactions } \\
& \mathrm{d} 710 \text { Basic interpersonal } \\
& \text { interactions } \\
& \mathrm{d} 720 \text { Complex interpersonal } \\
& \text { interactions } \\
& \mathrm{d} 729 \text { General interpersonal } \\
\text { interactions, other specified and } & \\
& \text { unspecified } \\
\text { d730-d779 Particular } \\
\text { interpersonal relationships } \\
\text { d798 Interpersonal interactions } \\
\text { and relationships, other } \\
\text { specified } \\
\text { d799 Interpersonal interactions } \\
\text { and relationships, unspecified }\end{array}$ & Usual activities & \\
\hline & & Chapter: Major Life Areas & & \\
\hline & & $\begin{array}{ll}\circ & \mathrm{d} 810-\mathrm{d} 839 \text { Education } \\
\circ & \mathrm{d} 840-\mathrm{d} 859 \text { Work and } \\
& \text { employment } \\
\circ & \mathrm{d} 860-\mathrm{d} 879 \text { Economic life } \\
\mathrm{d} 898 \text { Major life areas, other } \\
& \text { specified } \\
& \mathrm{d} 899 \text { Major life areas, } \\
& \text { unspecified }\end{array}$ & Usual activities & \\
\hline & & $\begin{array}{ll}\text { Chapter: Community, Social and Civic Life } \\
\circ & \text { d910 Community life } \\
\text { d920 Recreation and leisure } \\
\circ & \text { d930 Religion and spirituality } \\
\circ & \text { d940 Human rights } \\
\text { d950 Political life and } \\
\\
\text { citizenship } \\
\text { d998 Community, social and } \\
\text { civic life, other specified } \\
\text { d999 Community, social and } \\
\quad \text { civic life, unspecified }\end{array}$ & Usual activities & \\
\hline
\end{tabular}


Table 1. Cont

\begin{tabular}{|c|c|c|c|c|}
\hline \multicolumn{3}{|c|}{ International Classification of Functioning, Disability and Health (ICF) Classifications } & \multicolumn{2}{|c|}{ Instrument Dimensions } \\
\hline Domains & ICF Chapter & Specific ICF Chapters and Categories & EQ-5D-3L ${ }^{a}$ & Barthel Index \\
\hline Environmental Factors & $\begin{array}{ll}\text { - } & \text { Products and Technology } \\
\text { Natural Environment and } \\
\text { Human-Made Changes to } \\
\text { Environment } \\
\text { - Support and Relationships } \\
\text { - } \quad \text { Attitudes } \\
\text { Services, Systems and } \\
\text { Policies }\end{array}$ & N/A & N/A & $\mathrm{N} / \mathrm{A}$ \\
\hline
\end{tabular}

${ }^{\mathrm{a}}$ EQ-5D-3L = EuroQol 5 dimensions 3 levels; SF6D = Short Form 6 dimensions.

\subsection{Instruments}

\subsubsection{Barthel Index (BI)}

The BI is a measure of functional status whose validity when used on a general population of older people has been shown [22]. The BI uses 10 items. Each item is weighted according to the professional judgement of the instrument developer with different weights to measure a person's level of functional status (independence) [11]. Of the 10 items, two (bathing and grooming) are rated on a two-point scale of 0 and 1, six (feeding, dressing, bowels, bladder, toilet use and stairs) on a three-point scale of 0,1 and 2 and the last two items (transfers and mobility) are rated on a four-point scale of $0,1,2$ and 3 . An overall score ranging from 0 to 20 (which can also be standardized to range between 0 and 100) is obtained by adding the scores on each item [11]. Higher BI overall and item scores represent a greater level of independence. The reliability, sensitivity and suitability for the use of the BI in older populations have been reported in the literature [23-26].

\subsubsection{EuroQol-5-Dimensions 3 Level (EQ-5D-3L)}

The EQ-5D-3L is the three-level version of the EuroQol 5 Dimensions (EQ-5D) which is a standardized HRQoL questionnaire designed to produce a simple generic measure of health for use in clinical and economic appraisal for individuals aged $\geq 18$ years. The EQ-5D-3L measures five dimensions: mobility, self-care, usual activities, pain/discomfort and anxiety/depression [27]. Each domain has three levels of impairment ('no problems', 'some/moderate problems' and 'extreme' problems), allowing the EQ-5D-3L to distinguish between 243 states of health [28]. Based on UK general population preference weights determined through the time trade-off approach [28], utilities ranging from -0.59 to 1 can be attached to each of the EQ-5D-3L health states. Higher utilities represent better HRQoL. The EQ-5D-3L has strong psychometric properties, and its validity, when used in populations of older people, has been proven [29-32].

\subsection{Conceptual Overlap between Instruments and Hypotheses}

To depict the conceptual overlap between these instruments, the dimensions were compared using the International Classification of Functioning, Disability and Health (ICF) Core Set framework [33]. The ICF is the most comprehensive attempt to classify health concepts within a biopsychosocial model of health, functioning and disability [33]. It has been linked to many patient-reported outcome development efforts, including that of the PatientReported Outcomes Measurement Information System (PROMIS) [34,35]. The instrument dimensions were linked to the ICF classification allowing them to be categorized into three potential domains, namely 'body functions and structures' (measuring impairments to (i) physiological and psychological functions of body systems and (ii) anatomical parts of the body such as limbs), 'activities and participation' (referring to constructs that cover the full range of life areas such as execution of tasks or actions and involvement in life situations) and 'environmental factors' (referring to the physical, social and attitudinal environment in which people live and conduct their lives which can be either barriers 
or facilitators to their functioning) [33]. Each of these domains was broken down into chapters, which were broken down further into categories (Table 1).

We, therefore, hypothesized that there would be moderate convergent validity between BI items and/or EQ-5D-3L dimensions that belonged to the same ICF domains. We also hypothesized that both instruments would discriminate between BI items and EQ-5D-3L dimensions that belonged to different ICF domains, i.e., the absolute correlation between these items and dimensions would be lower than that for items and dimensions belonging to the same ICF domains.

\subsection{Statistical Analysis}

Descriptive statistics of participants were estimated. The distribution of the BI and EQ-5D-3L was tested for normality using the Shapiro-Francia test (EQ-5D-3L: skewness $=-1.030006$, Kurtosis $=3.505952$, z-score $=10.678, p<0.001$; BI: skewness $=-1.197832$, Kurtosis $=4.111406$, z-score $=10.234, p<0.001)$. Based on this test, appropriate nonparametric statistical tests of difference were applied.

Convergent validity evaluates the extent to which constructs that are expected to be related are, in fact, related [36]. The convergent validity of the BI item/total scores and EQ-5D-3L dimension/utility scores was assessed using several approaches. First, the level of association between BI item and EQ-5D-3L dimension scores was evaluated using Kendall's Tau-B rank correlation coefficients, which have been recommended for ordinal categorical data [37]. We expected to see correlation between dimensions or items that theoretically belonged to the same ICF domains. Correlations below 0.30 were considered weak, those between 0.40 and 0.50 moderate and those above 0.50 strong (indicating that instruments were measuring similar constructs) [38]. Second, exploratory factor analysis (EFA) [39], incorporating polychoric correlation matrices, estimated using the robust weighted least squares approach, to accommodate the categorical nature of the instrument item/dimension responses [40,41], was undertaken. A decision to carry out EFA rather than confirmatory factor analysis (CFA) was driven by the fact that it was impossible to have a firm idea about the number of factors to be encountered and about which items/dimensions would most likely load onto each factor [39]. As recommended in the literature [42], only correlations $\geq 0.3$ were considered to represent significant correlation in the EFA. The number of factors to include was determined by examining scree plots from the EFA. Due to this exercise's exploratory nature, the EFA interpretation was based on a 'varimax orthogonal rotated' solution [43]. Convergence between the instruments was confirmed by BI items loading significantly onto the same factors as the EQ-5D-3L dimensions. Third, scatter plots between BI total and EQ-5D-3L utility scores were examined. The strength of convergence at the total/utility score level was further assessed by the size of Krippendorff's alpha (estimating the levels of reliability between the instruments) [44] and the correlation coefficient (measuring the level of association between the instruments) [38]. An alpha of 0.80 or over-represented good agreement [45]. Lastly, modified Bland-Altman plots were also used to further study the limits of agreement between the two instruments. As recommended in the literature [46], standardized Z scores of utilities/total scores were calculated for the modified plots because the instruments use different rating scales leading to marked differences in the magnitude of the scores (i.e., the maximum BI total scores can be up to 169 times larger than those for the EQ-5D-3L). Utilities and total scores were power transformed to follow a normal distribution before calculating Z scores.

Campbell and Fiske [47] posit that different measures of the same hypothetical construct should correlate highly with one another if the measures are valid. In terms of convergent validity, therefore, we hypothesized, based on the content and descriptions of the instruments [11], that there would be a moderate to strong correlation between conceptually related items and dimensions, e.g., between the 'mobility' item of the BI and the 'mobility dimension of the EQ-5D-3L. Specific hypotheses are presented in Table 2. 
Table 2. Baseline characteristics of the study participants.

\begin{tabular}{|c|c|c|}
\hline Characteristic $^{a}$ & Mean (SD) ${ }^{b}$ & Median (IQR) ${ }^{\mathbf{b}}$ \\
\hline Age & $78(11)$ & $80(73,86)$ \\
\hline EQ-5D-3L utility score & $0.499(0.351)$ & $0.587(0.26,0.743)$ \\
\hline BI total score & $79.32(19.465)$ & $85(70,95)$ \\
\hline EQ-5D-3L utility Z-score ${ }^{c}$ & $-0.002(0.999)$ & $0.248(-0.684,0.692)$ \\
\hline BI total Z-score ${ }^{\mathrm{c}}$ & $0.001(1)$ & $0.292(-0.479,0.806)$ \\
\hline Characteristic & $n(\%)$ & \\
\hline \multicolumn{3}{|l|}{ Gender } \\
\hline Male & $515(30)$ & \\
\hline Female & $1175(70)$ & \\
\hline \multicolumn{3}{|l|}{ Living Arrangements } \\
\hline No & $748(44)$ & \\
\hline Yes & $942(56)$ & \\
\hline \multicolumn{3}{|c|}{ Type of Intermediate care rehabilitation service ${ }^{d}$} \\
\hline Acute Admission avoidance & $659(39)$ & \\
\hline Supported Discharge & $961(57)$ & \\
\hline Residential & $70(4)$ & \\
\hline
\end{tabular}

Discriminant validity assesses the extent to which constructs that theoretically should not be highly related to each other are, in fact, not found to be highly correlated to each other [48]. Two approaches were used to determine discriminant validity. Firstly, the correlation between EQ-5D-3L dimensions and BI items that theoretically did not belong to the same ICF domains was established. We expected discriminant validity coefficients to be smaller in magnitude than convergent validity coefficients [48]. Secondly, the discriminant ability of the instruments was tested using EFA by assessing whether BI items and EQ-5D3L dimensions loaded more highly onto their own factor than to another or other factors. Cases where the variance extracted estimate (AVE) was greater than the squared correlation estimate $\left(\mathrm{Corr}^{2}\right)$ were indicative of good discriminant validity [49].

For discriminant validity, we postulated that discriminant validity coefficients would be smaller in magnitude than convergent validity coefficients for both instruments. We also expected the BI items and EQ-5D-3L dimensions to load more highly onto their own factors due to differences in the health constructs they were designed to measure [27].

\section{Results}

\subsection{Participant Characteristics}

Of the 2253 who were recruited, 1690 had complete data for both BI and EQ-5D-3L. Characteristics for 1690 study respondents are presented in Table 2 . The mean \pm standard deviation (SD) values for the BI total and EQ-5D-3L utility scores were 79.320 \pm 19.465 and $0.499 \pm 0.351$, respectively.

Both instruments had non-normal distributions $(p<0.0001$, Shapiro-Francia test; Figure 1). Therefore, non-parametric tests of differences were applied to all analyses reported below. 


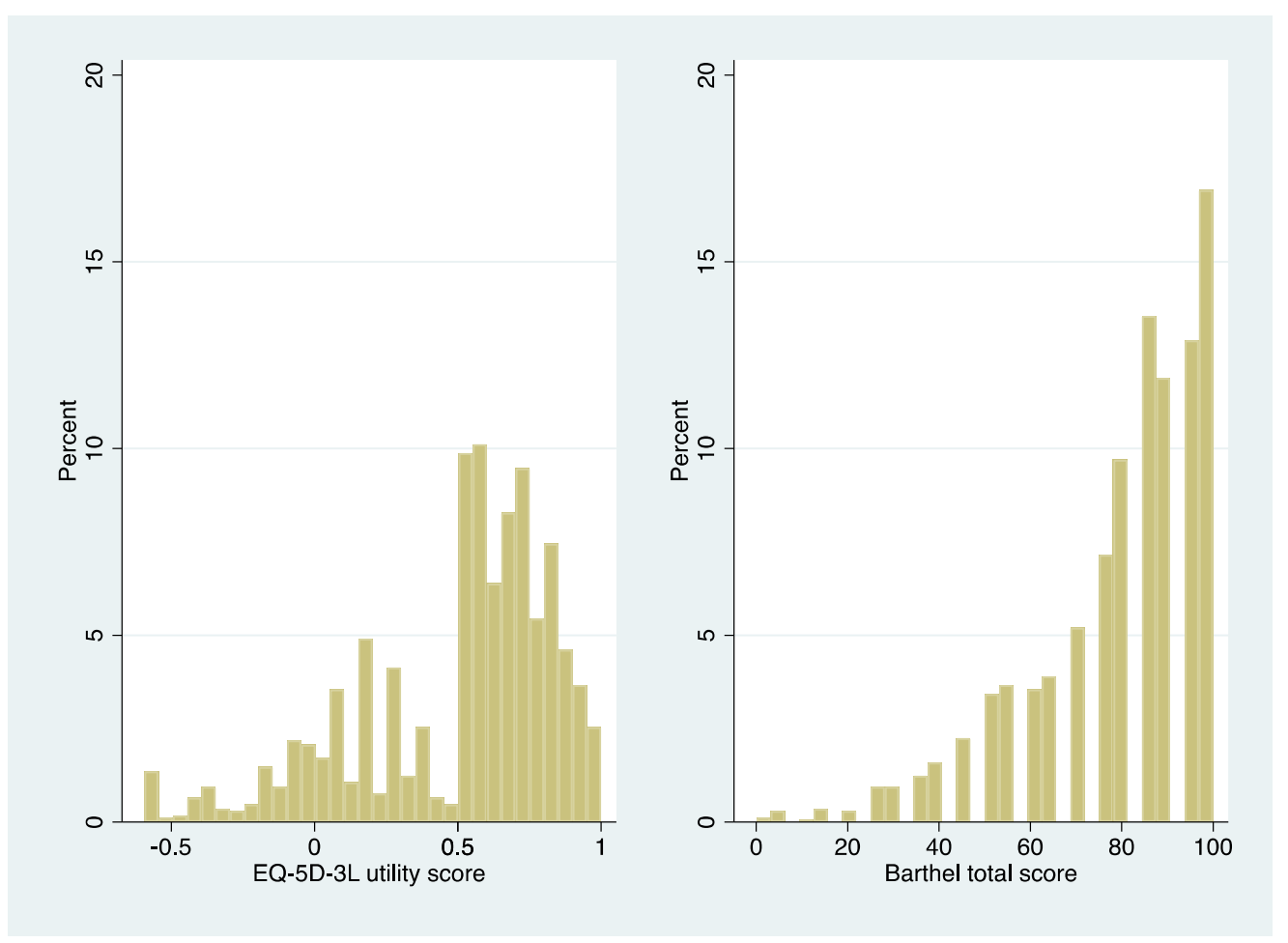

Figure 1. Presents the distribution of EuroQol 5 dimensions 3 levels (EQ-5D-3L) utilities and Barthel index (BI) total scores.

\subsection{Conceptual Overlap between Instruments}

Analysis of the conceptual overlap of the EQ-5D-3L and BI revealed that the dimensions of both instruments capture domains related to 'Body functions' and 'Activities and Participation', as shown in Table 2. Two EQ-5D-3L dimensions (Anxiety/depression and Pain/discomfort) and two BI items (Bowels and Bladder) were classified under the same ICF domain of 'Body Functions', but a more detailed analysis showed that each of these four dimensions belonged to different chapters within this domain (Table 2). The most overlap was in terms of EQ-5D-3L dimensions (three out of five) and BI items (eight out of 10) that captured the ICF domain of 'Activities and Participation'. The EQ-5D-3L dimension of 'Mobility' and the BI items of 'Mobility', 'Stairs' and 'Transfer' belonged to the 'Mobility' chapter of the 'Activities and Participation' domain. Further, the EQ-5D-3L dimension of 'Self-Care' and the BI items of 'Bathing', 'Grooming', 'Feeding', 'Dressing' and 'Toilet use' belonged to the 'Self-Care' chapter of the 'Activities and Participation' domain. The 'usual activities' dimension of the EQ-5D-3L could separately be potentially linked to the four ICF 'Activities and Participation' domain chapters: 'Domestic Life', 'Interpersonal Interactions and Relationships', 'Major Life Areas' and 'Community, Social and Civic Life'. Overall, our analysis showed a considerable correlation between the two instruments as all EQ-5D-3L dimensions and BI items showed conceptual overlap at the ICF domain level. When the domains were broken down into chapters, our analysis showed conceptual overlap between two EQ-5D-3L dimensions and eight BI items.

\subsection{Convergent Validity}

Table 3 presents bivariate correlation coefficients, all statistically significant at a $5 \%$ significance level, depicting the relationship between BI item and EQ-5D-3L dimension scores. The results of this analysis show that there was weak to moderate statistically significant negative association (Spearman's correlation, $p$-value $<0.001$ ) between the two instruments ranging from -0.11 ('Bathing' (BI) versus 'Pain/Discomfort' (EQ-5D-3L)) and ('Feeding' (BI) versus 'Anxiety/Depression' (EQ-5D-3L)) to 0.54 ('Dressing' (BI) versus 'Self-care' (EQ-5D-3L)). As was hypothesized, correlations between BI items and EQ-5D-3L 
dimensions measuring similar constructs were in the direction expected, but some were weak rather than moderate. Our analysis shows that the absolute correlation between dimensions or items that theoretically belonged to the same ICF domains was on average 0.43 (between BI items), 0.41 (between EQ-5D-3L dimensions) and 0.36 (between EQ-5D-3L dimensions and BI items).

The results from the EFA shown in Table 4 depict the association between the items/ dimensions of the instruments and latent or unobserved constructs. An examination of the scree plot (available from the author upon request) from this analysis suggested that extracting two factors was adequate. Table 4 shows that all BI items loaded more highly onto factor 1 (factor loadings $\geq 0.57$ ), indicating that they are all associated with the latent variable or construct represented by this factor. However, only two EQ-5D-3L dimensions ('self-care' and 'usual activities') were also associated with this factor. Similarly, all EQ-5D$3 \mathrm{~L}$ dimensions loaded more highly onto factor 2 (factor loadings $\geq 0.64$ ) with only five BI items also loading highly onto this factor, i.e., 'dressing', 'toilet use', 'transfers', 'mobility' and 'stairs'. There was some cross-loading in the EFA as well, with some BI items and EQ-5D-3L dimensions loading onto both factors.

At the total/utility score level, a scatter plot between the two instruments (Figure 2) suggests a moderate correlation between them. This was confirmed by the size of Spearman's correlation coefficient ( $r=0.51$, Figure 2$)$ and Krippendorff's alpha (0.52, Figure 2).

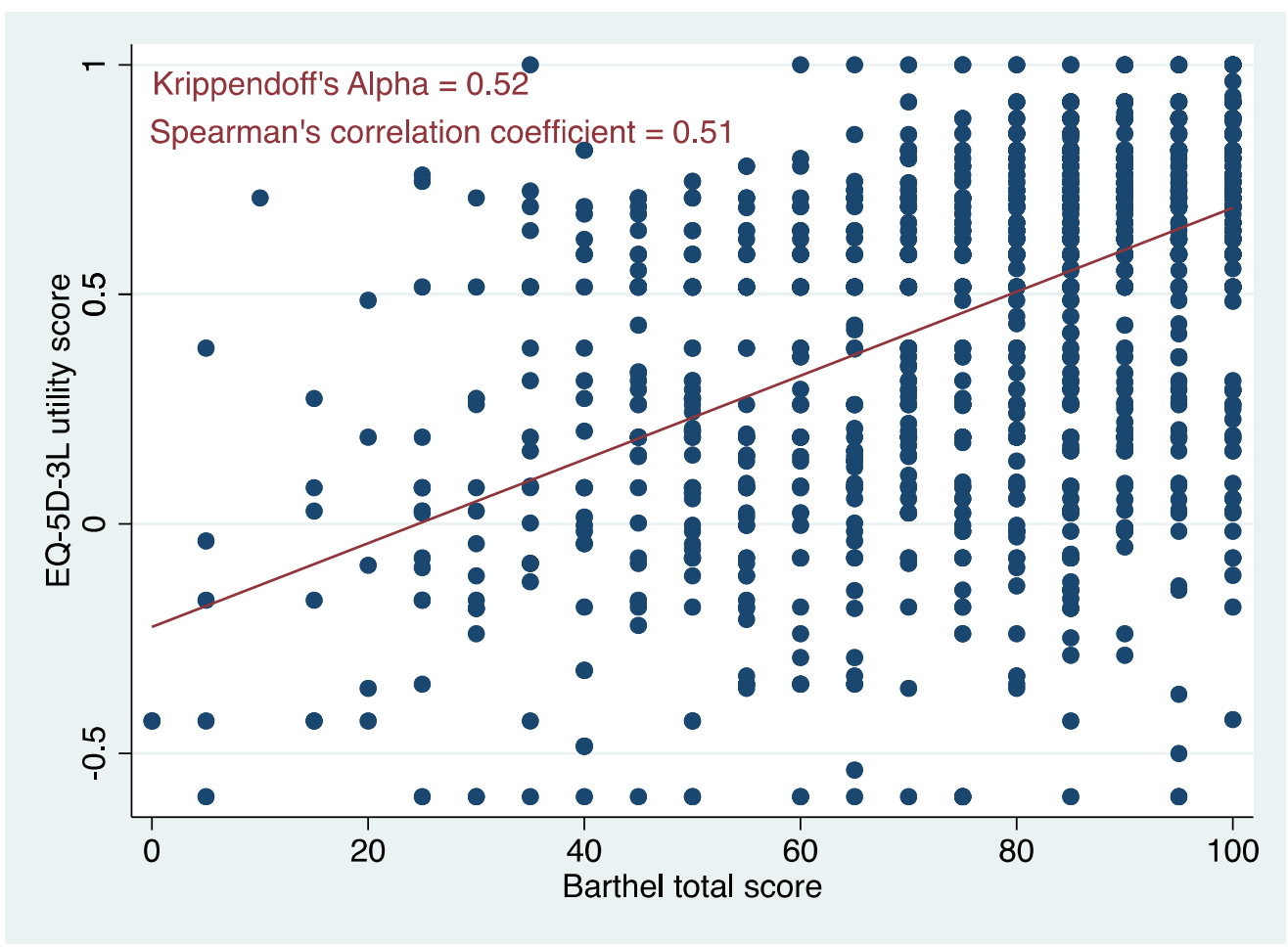

Figure 2. Shows a scatter plot between EuroQol 5 dimensions 3 levels (EQ-5D-3L) utilities and Barthel index total scores. 


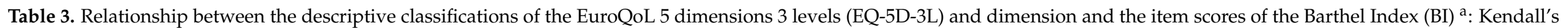
Tau-B rank correlation coefficients showing correlation between the EQ-5D-3L dimension and BI item scores ${ }^{\mathrm{a}}$.

\begin{tabular}{|c|c|c|c|c|c|c|c|c|c|c|c|c|c|c|c|c|}
\hline & & \multicolumn{5}{|c|}{ EQ-5D-3L ${ }^{\mathrm{b}}$ Dimensions } & \multicolumn{10}{|c|}{ Barthel $^{\mathrm{b}}$ Items } \\
\hline & & Mobility & Self-Care & $\begin{array}{c}\text { Usual } \\
\text { Activities }\end{array}$ & Pain/Discomfort & Anxiety/Depression & Feeding & Bathing & Grooming & Dressing & Bowels & Bladder & Toilet Use & Transfers & Mobility & Stairs \\
\hline \multirow{3}{*}{$\begin{array}{l}\text { EQ-5D-3L } \\
\text { Dimen- } \\
\text { sions }\end{array}$} & $\begin{array}{l}\text { Mobility } \\
\text { Self-care }\end{array}$ & $\begin{array}{c}- \\
0.45\end{array}$ & - & & & & $\frac{-0.17}{-0.29}$ & $\frac{-0.20}{-0.35}$ & $\frac{-0.22}{-0.42}$ & $\frac{-0.25}{-0.54}$ & $\begin{array}{l}-0.14 \\
-0.17\end{array}$ & $\begin{array}{l}-0.16 \\
-0.20\end{array}$ & $\frac{-0.28}{-0.39}$ & $\frac{-0.31}{-0.40}$ & $\frac{-0.31}{-0.36}$ & $\frac{-0.28}{-0.29}$ \\
\hline & $\begin{array}{l}\text { Usual } \\
\text { activities }\end{array}$ & $\overline{0.39}$ & $\underline{0.46}$ & - & & & $\overline{-0.22}$ & $\overline{-0.29}$ & $\overline{-0.28}$ & $\overline{-0.37}$ & -0.09 & -0.12 & $\overline{-0.30}$ & $\overline{-0.32}$ & $\overline{-0.30}$ & -0.26 \\
\hline & $\begin{array}{l}\text { Pain } \\
\text { Anxiety }\end{array}$ & $\begin{array}{l}0.35 \\
0.28\end{array}$ & $\begin{array}{l}0.27 \\
0.32\end{array}$ & $\begin{array}{l}0.28 \\
0.28\end{array}$ & $\underline{0.32}$ & - & $\begin{array}{l}-0.12 \\
-0.11\end{array}$ & $\begin{array}{l}-0.11 \\
-0.16\end{array}$ & $\begin{array}{l}-0.14 \\
-0.20\end{array}$ & $\begin{array}{l}-0.17 \\
-0.24\end{array}$ & $\frac{-0.06}{-0.11}$ & $\frac{-0.06}{-0.14}$ & $\begin{array}{l}-0.16 \\
-0.24\end{array}$ & $\begin{array}{l}-0.20 \\
-0.25\end{array}$ & $\begin{array}{l}-0.19 \\
-0.26\end{array}$ & $\begin{array}{l}-0.17 \\
-0.15\end{array}$ \\
\hline \multirow{10}{*}{$\begin{array}{l}\text { Barthel } \\
\text { Index } \\
\text { Items }\end{array}$} & Feeding & & & & & & - & & & & & & & & & \\
\hline & Bathing & & & & & & $\underline{0.21}$ & - & & & & & & & & \\
\hline & Grooming & & & & & & $\overline{0.38}$ & $\underline{0.38}$ & - & & & & & & & \\
\hline & Dressing & & & & & & $\frac{0.40}{0.40}$ & $\frac{0.42}{0.42}$ & $\underline{0.64}$ & - & & & & & & \\
\hline & Bowels & & & & & & $\frac{0.40}{0.19}$ & $\frac{0.42}{0.10}$ & $\frac{.04}{0.24}$ & 0.19 & - & & & & & \\
\hline & $\begin{array}{l}\text { Dowels } \\
\text { Bladder }\end{array}$ & & & & & & 0.24 & 0.18 & 0.32 & 0.31 & 0.38 & 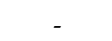 & & & & \\
\hline & Toilet use & & & & & & 0.44 & 0.30 & 0.53 & 0.55 & 0.26 & 0.35 & - & & & \\
\hline & Transfers & & & & & & $\overline{0.40}$ & 0.28 & 0.50 & $\overline{0.54}$ & 0.26 & $\overline{0.34}$ & 0.74 & - & & \\
\hline & Mobility & & & & & & $\frac{0.36}{0.36}$ & $\frac{0.28}{0.28}$ & $\frac{0.46}{0.46}$ & 0.50 & 0.24 & 0.32 & 0.70 & 0.74 & - & \\
\hline & Stairs & & & & & & $\underline{0.18}$ & $\underline{0.40}$ & $\underline{0.33}$ & 0.38 & $\underline{\underline{0.19}}$ & $\underline{0.22}$ & $\underline{0.34}$ & $\underline{0.34}$ & $\underline{0.38}$ & - \\
\hline
\end{tabular}

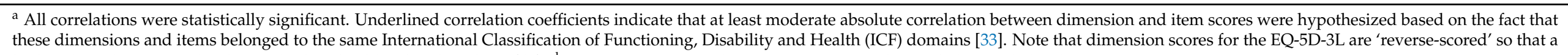
higher (lower) score implies lower (higher) health-related quality of life. ${ }^{\mathrm{b}}$ EQ-5D-3L = EuroQol 5 Dimensions 3 Levels. Barthel = Barthel Index. 
Table 4. Results of the exploratory factor analysis showing which factors the EuroQoL 5 dimensions 3 levels (EQ-5D-3L) dimensions and the Barthel Index (BI) items loaded onto a .

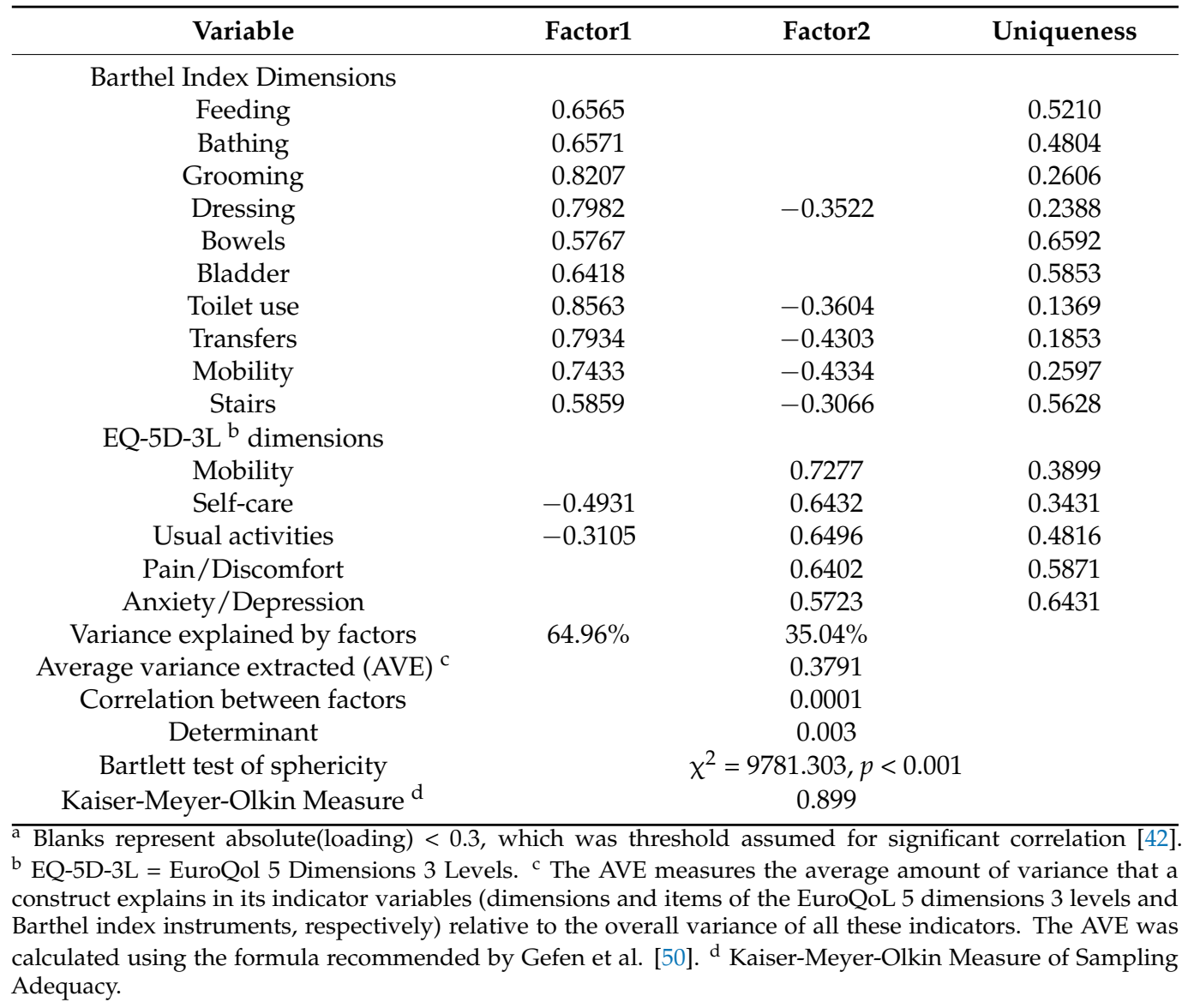

The modified Bland-Altman scatter plots in Figure 3 also suggest moderate agreement between the two instruments, with only about $6 \%$ of the $\mathrm{Z}$ scores outside the $95 \%$ limits of agreement.

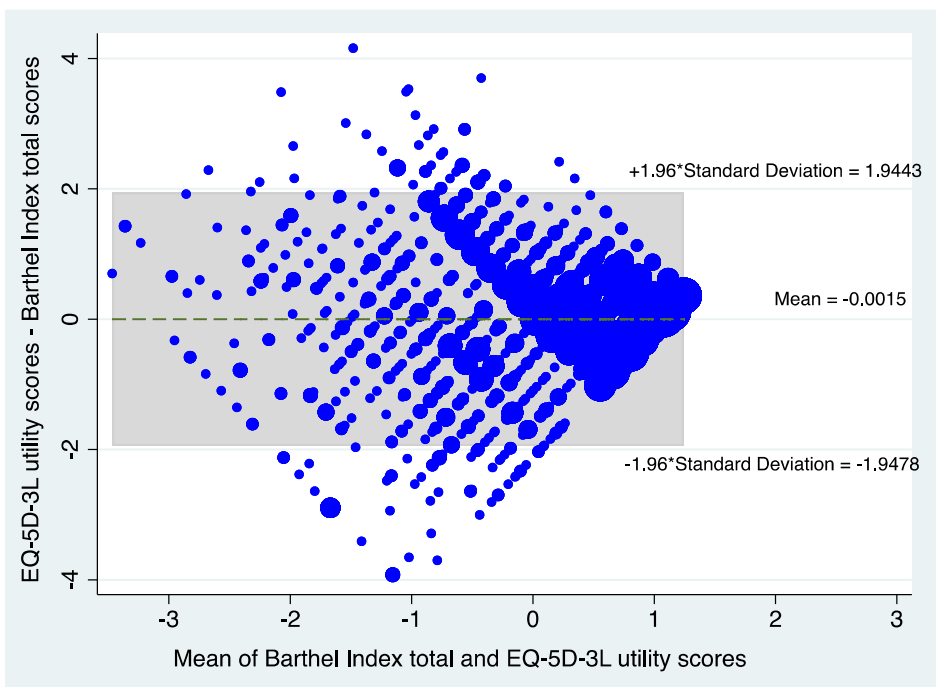

Figure 3. Presents the Bland and Altman Plot showing the level of agreement between the EuroQol 5 dimensions 3 levels (EQ-5D-3L) utility standardized $Z$ scores versus Barthel index total standardized Z scores. 


\subsection{Discriminant Validity}

The results of this analysis (Table 3) show that the absolute correlation between dimensions or items that did not theoretically belong to the same ICF domains ('Body Functions' versus 'Activities and Participation') was on average 0.25 (between BI items), 0.30 (between EQ-5D-3L dimensions) and 0.22 (between EQ-5D-3L dimensions and BI items). These results also suggest that the BI had marginally better discriminant validity (lower discriminant validity coefficients) than the EQ-5D-3L. Overall, the discriminant validity coefficients were smaller in magnitude than the convergent validity coefficients.

The results of the EFA suggested that the BI items and EQ-5D-3L dimensions were able to discriminate between factors that they loaded onto as the estimate of the AVE (0.3791) was greater than that for $\operatorname{Corr}^{2}(0.0001)$.

\section{Discussion}

Using data from a population of older people receiving rehabilitation services, the present study reports on the first head-to-head empirical comparison between the $\mathrm{BI}$, an instrument recommended for assessing functional status [11], and the EQ-5D-3L, a generic HRQoL instrument recommended for use within CUA [12]. When considering health status measures for potential use in economic evaluation within rehabilitation research targeted at older people, our analysis shows that the two instruments are both suitable as they were able to demonstrate discriminant validity. However, they need to be considered complements rather than substitutes for each other due to moderate convergence between them. The decision about which instrument to use and in which context should be guided by the ICF domain chapters the dimension or items load onto. If it is important to capture information on mental functions, sensory functions and pain, domestic tasks, interpersonal interactions and relationships, and community, social and civic life, then the EQ-5D-3L should be chosen. However, if it is more important to capture information on mobility and self-care, then the BI should be selected as it has more items capturing these two constructs than the EQ-5D-3L. An added consideration would be whether there is a desire for the economic evaluation results based on either instrument to be compared across sectors (i.e., compared to non-rehabilitation or aged care sectors using a CUA) or not. If the former is required, then the EQ-5D-3L would be the ideal measure and the BI if the latter is desired. Further, consideration should also be made to the descriptive basis of the two instruments as they differ in some respects with the scoring systems based on entirely different approaches, i.e., the BI being a scale with cardinal properties and the EQ-5D-3L being a semi-weighted ordinal scale. The EQ-5D-3L has been long established as the most widely used preference-based instrument worldwide. For instance, within economic evaluations, it is the most popular overall [43] and one of the most frequently used for services targeted at older people [13,14]. The development of a new five-level version of the instrument has improved its sensitivity and standardized the language across dimensions [51]. Similar to the EQ-5D-3L, the BI discriminated well between factors measuring latent constructs captured by the instrument and between dimensions of the EQ-5D-3L. Due to having discriminant validity comparable to that of the EQ-5D-3L, the BI would be equally valuable for measuring subgroup differences in studies where the former is routinely used, such as within economic evaluation. In economic evaluations and particularly in CEA, however, the BI can be used to measure non-utility-based functional status as it does not have utility weights.

As hypothesized, based on the ICF domains that BI and EQ-5D-3L items loaded on (Table 1), results from the bivariate correlation analysis and the EFA showed statistically significant convergence between items on the BI and EQ-5D-3L dimensions that measured similar constructs. However, the level of correlation was weak to moderate rather than moderate to strong. One explanation of these findings is the possibility that some pairwise correlations between items and dimensions were low because of unaccounted-for, unrecognized and unmeasured constructs that link them together that may not be adequately captured by the ICF framework [52]. For instance, it was possible that someone who can 
perform their 'usual activities' on the EQ-5D-3L may still not control their 'bowels' on the BI if they have a chronic bowel problem. Respondents may therefore view the lack of bowel control as 'usual' because they have adapted to a chronic condition. A similar finding was reported elsewhere [53]. Even though the BI items loaded highly onto different factors compared to the EQ-5D-3L dimensions in the EFA, there was sufficient overlap between some of these items and dimensions suggestive of moderate levels of agreement $(>0.3)$. It is not surprising that the EFA suggested that the 'self-care' and 'usual activities' dimensions of the EQ-5D-3L measured similar latent constructs such as those of the BI. In an EFA comparing the EQ-5D-3L to the ICECAP-O, Keeley et al. [54] posited that these two EQ-5D-3L dimensions represent a single factor termed "physical functioning", which is one of the critical constructs captured in the design of the BI. At the BI total/EQ-5D-31 utility score level, estimates of Spearman's correlation coefficient and Krippendorff's alpha, as well as an examination of the Bland-Altman plot, all suggest a moderate correlation between the instruments. This means that when all instrument items and dimensions are considered in their totality, they, on average, represent interrelated concepts. This has been shown in our other research [55-57].

The EFA showed that BI items and EQ-5D-3L dimensions each loaded more highly onto their own factor (factor 1 and 2, respectively; Table 3). Based on the dominance of items and dimensions that assess functional status associated with factor 1, we can characterize it as measuring 'physical functioning'. We can further represent factor 2 as "wellbeing", which has been suggested as a broader concept that captures the attributes such as those that loaded onto this factor [54]. An examination of the sizes of the factor loadings from the EFA suggests that these instruments should be seen as complements rather than substitutes for each other. This is because the only two EQ-5D-3L dimensions that loaded onto the 'physical functioning' factor ('self-care' and 'usual activities') did not load as highly as the BI items. Similarly, the five BI items that loaded onto the 'wellbeing' factor did not load as highly onto this factor as the EQ-5D-3L dimensions. This result supports the view that the BI can measure functioning-related aspects of health better than the generic HRQoL instrument. On the other hand, the size of the EQ-5D-3L loadings onto the 'wellbeing' factor suggest that this instrument can measure broader aspects of health better than the BI. This result has also been seen elsewhere [58].

Some limitations merit note. The analysis in this study focused on comparisons between two instruments collected using a cross-sectional study design. Therefore, future research should consider assessing the instruments' responsiveness over time based on a longitudinal study design. Doing so will facilitate the evaluation of the capability of these instruments to detect clinically important changes over time in this population, a property important for assessing incremental effectiveness [59,60]. Additionally, consideration should also be given to extending the comparisons to other instruments designed for application with older people, such as the ICECAP-O, as these focus on quality-of-life constructs not presently captured in this study, such as individual capabilities [61,62].

\section{Conclusions}

There is no gold standard for measuring outcomes in populations of older people due to the heterogeneous impacts that conditions affecting them may have on health status, physical functioning and quality of life. As a result, an assessment of the convergent validity of one instrument when compared against another can only be implied rather than proved. However, our analysis shows that the BI has comparable discriminant validity, a property that is useful when conducting subgroup analysis. To capture more 'activitiesand-participation-specific ICF constructs not measured by a generic HRQoL instrument such as the EQ-5D-3L, the BI can be used within rehabilitation research. In cases where the focus is on capturing information on more 'body-function-specific' ICF constructs, then the BI should be selected as it has more items capturing this construct than the EQ-5D-3L.

Author Contributions: B.K.: conceptualization, methodology, data acquisition, data analysis, interpretation of results, original draft preparation, editing; N.B.B.: data analysis, interpretation of results, 
editing; C.M.-K.: data analysis, interpretation of results, editing; R.O.: data analysis, interpretation of results, editing. All authors have read and agreed to the published version of the manuscript.

Funding: This research received no external funding.

Institutional Review Board Statement: The study was conducted according to the guidelines of the Declaration of Helsinki, and approved by The Trent Multicentre Research Ethics Committee, UK.

Informed Consent Statement: Informed consent was obtained from all subjects involved in the study.

Data Availability Statement: Data used in this study are available from the authors upon request.

Conflicts of Interest: The authors declare no conflict of interest.

\section{References}

1. Khanna, D.; Tsevat, J. Health-related quality of life-an introduction. Am. J. Manag. Care 2007, 13 (Suppl. S9), S218-S223.

2. Bierman, A.S. Functional Status: The Sixth Vital Sign. J. Gen. Intern. Med. 2001, 16, 785-786. [CrossRef]

3. Beswick, A.D.; Rees, K.; Dieppe, P.; Ayis, S.; Gooberman-Hill, R.; Horwood, J.; Ebrahim, S. Complex interventions to improve physical function and maintain independent living in elderly people: A systematic review and meta-analysis. Lancet 2008, 371 , 725-735. [CrossRef]

4. Halvorsrud, L.; Kirkevold, M.; Diseth, A.; Kalfoss, M. Quality of life model: Predictors of quality of life among sick older adults. Res. Theory Nurs Pr. 2010, 24, 241-259. [CrossRef]

5. Simone, P.M.; Haas, A.L. Frailty, Leisure Activity and Functional Status in Older Adults: Relationship With Subjective Well Being. Clin. Gerontol. 2013, 36, 275-293. [CrossRef]

6. Sims, J. Healthy ageing. Aust. Fam. Phys. 2017, 46, 26-29. [PubMed]

7. World Health Organisation Rehabilitation: Key Facts. Available online: https://www.who.int/news-room/fact-sheets/detail/ rehabilitation (accessed on 24 August 2021).

8. Stolov, W.C.; Clowers, M.R. Handbook of Severe Disability: A Text. for Rehabilitation Counselors, Other Vocational Practitioners, and Allied Health Professionals; U.S. Government Printing Office: Washington, DC, USA, 1981.

9. Cohen, M.E.; Marino, R.J. The tools of disability outcomes research functional status measures. Arch. Phys. Med. Rehabil. 2000, 81, S21-S29. [CrossRef] [PubMed]

10. Hall, W.J. Update in geriatrics. Ann. Intern. Med. 1997, 127, 557-564. [CrossRef] [PubMed]

11. Mahoney, F.I.; Barthel, D.W. Functional Evaluation: The Barthel Index. Md. State Med. J. 1965, 14, 61-65. [PubMed]

12. National Institute for Health and Care Excellence Guide to the Methods of Technology Appraisal 2013; NICE: London, UK, 2013.

13. Makai, P.; Brouwer, W.B.; Koopmanschap, M.A.; Stolk, E.A.; Nieboer, A.P. Quality of life instruments for economic evaluations in health and social care for older people: A systematic review. Soc. Sci. Med. 2014, 102, 83-93. [CrossRef] [PubMed]

14. Bulamu, N.B.; Kaambwa, B.; Ratcliffe, J. A systematic review of instruments for measuring outcomes in economic evaluation within aged care. Health Qual. Life Outcomes 2015, 13, 179. [CrossRef]

15. Brazier, J.E.; Deverill, M.; Green, C.; Harper, R.; Booth, A. A review of the use of health status measures in economic evaluation. Health Technol. Assess. 1999, 3, 1-164. [CrossRef]

16. Furlong, W.; Barr, R.D.; Feeny, D.; Yandow, S. Patient-focused measures of functional health status and health-related quality of life in pediatric orthopedics: A case study in measurement selection. Health Qual. Life Outcomes 2005, 3, 3. [CrossRef]

17. Royal College of Physicians Report of Joint Workshops of the Research Unit of the Royal College of Physicians and the British Geriatrics Society. Standardised Assessment Scales for Elderly People; Royal College of Physicians: London, UK, 1992.

18. Wilkinson, P.R.; Wolfe, C.D.; Warburton, F.G.; Rudd, A.G.; Howard, R.S.; Ross-Russell, R.W.; Beech, R. Longer term quality of life and outcome in stroke patients: Is the Barthel index alone an adequate measure of outcome? Qual. Health Care 1997, 6, 125-130. [CrossRef]

19. Barton, P.; Bryan, S.; Glasby, J.; Hewitt, G.; Jagger, C.; Kaambwa, B.; Martin, G.; Nancarrow, S.A.; Parker, S.; Regen, E.; et al. A National Evaluation of the Costs and Outcomes of Intermediate Care for Older People; Intermediate Care National Evaluation Team (ICNET): Birmingham, UK, 2006.

20. Lu, W.S.; Huang, S.L.; Yang, J.F.; Chen, M.H.; Hsieh, C.L.; Chou, C.Y. Convergent validity and responsiveness of the EQ-5D utility weights for stroke survivors. J. Rehabil Med. 2016, 48, 346-351. [CrossRef]

21. Kaambwa, B.; Bryan, S.; Barton, P.; Parker, H.; Martin, G.; Hewitt, G.; Parker, S.; Wilson, A. Costs and health outcomes of intermediate care: Results from five UK case study sites. Health Soc. Care Community 2008, 16, 573-581. [CrossRef]

22. Della Pietra, G.L.; Savio, K.; Oddone, E.; Reggiani, M.; Monaco, F.; Leone, M.A. Validity and reliability of the Barthel index administered by telephone. Stroke A J. Cereb. Circ. 2011, 42, 2077-2079. [CrossRef]

23. Bouwstra, H.; Smit, E.B.; Wattel, E.M.; van der Wouden, J.C.; Hertogh, C.; Terluin, B.; Terwee, C.B. Measurement Properties of the Barthel Index in Geriatric Rehabilitation. J. Am. Med. Dir. Assoc. 2019, 20, 420-425.e1. [CrossRef] [PubMed]

24. Hormozi, S.; Alizadeh-Khoei, M.; Sharifi, F.; Taati, F.; Aminalroaya, R.; Fadaee, S.; Angooti-Oshnari, L.; Saghebi, H. Iranian Version of Barthel Index: Validity and Reliability in Outpatients' Elderly. Int. J. Prev. Med. 2019, 10, 130. [PubMed] 
25. Green, J.; Forster, A.; Young, J. A test-retest reliability study of the Barthel Index, the Rivermead Mobility Index, the Nottingham Extended Activities of Daily Living Scale and the Frenchay Activities Index in stroke patients. Disabil. Rehabil. 2001, 23, 670-676. [CrossRef]

26. Taghizadeh, G.; Martinez-Martin, P.; Meimandi, M.; Habibi, S.A.H.; Jamali, S.; Dehmiyani, A.; Rostami, S.; Mahmuodi, A.; Mehdizadeh, M.; Fereshtehnejad, S.M. Barthel Index and modified Rankin Scale: Psychometric properties during medication phases in idiopathic Parkinson disease. Ann. Phys. Rehabil. Med. 2020, 63, 500-504. [CrossRef]

27. Brazier, J.E.; Ratcliffe, J.; Salomon, J.A.; Tsuchiya, A. Measuring and Valuing Health Benefits for Economic Evaluation, 2nd ed.; Oxford University Press: Oxford, UK, 2017.

28. Dolan, P. Modeling valuations for EuroQol health states. Med. Care 1997, 35, 1095-1108. [CrossRef]

29. Coast, J.; Peters, T.J.; Richards, S.H.; Gunnell, D.J. Use of the EuroQoL among elderly acute care patients. Qual. Life Res. 1998, 7, 1-10. [CrossRef] [PubMed]

30. Brazier, J.E.; Walters, S.J.; Nicholl, J.P.; Kohler, B. Using the SF-36 and Euroqol on an elderly population. Qual. Life Res. 1996, 5, 195-204. [CrossRef]

31. Lyons, R.A.; Crome, P.; Monaghan, S.; Killalea, D.; Daley, J.A. Health status and disability among elderly people in three UK districts. Age Ageing 1997, 26, 203-209. [CrossRef]

32. van den Bos, G.A.; Triemstra, A.H. Quality of life as an instrument for need assessment and outcome assessment of health care in chronic patients. Qual. Health Care 1999, 8, 247-252. [CrossRef]

33. World Health Organization. Towards a Common Language for Functioning, Disability and Health ICF: The International Classification of Functioning, Disability and Health; World Health Organization: Geneva, Switzerland, 2002.

34. Tucker, C.A.; Cieza, A.; Riley, A.W.; Stucki, G.; Lai, J.S.; Bedirhan Ustun, T.; Kostanjsek, N.; Riley, W.; Cella, D.; Forrest, C.B. Concept analysis of the patient reported outcomes measurement information system (PROMIS((R))) and the international classification of functioning, disability and health (ICF). Qual. Life Res. Int. J. Qual. Life Asp. Treat. Care Rehabil. 2014, 23, 1677-1686. [CrossRef]

35. Tucker, C.A.; Escorpizo, R.; Cieza, A.; Lai, J.S.; Stucki, G.; Ustun, T.B.; Kostanjsek, N.; Cella, D.; Forrest, C.B. Mapping the content of the Patient-Reported Outcomes Measurement Information System (PROMIS(R)) using the International Classification of Functioning, Health and Disability. Qual. Life Res. Int. J. Qual. Life Asp. Treat. Care Rehabil. 2014, 23, 2431-2438. [CrossRef]

36. Domino, G.; Domino, M.L. Psychological Testing: An. Introduction, 2nd ed.; Cambridge University Press: Cambridge, UK, 2006.

37. Kendall, M.G. A New Measure of Rank Correlation. Biometrika 1938, 30, 81-93. [CrossRef]

38. Tinetti, M.E.; Doucette, J.; Claus, E.; Marottoli, R. Risk factors for serious injury during falls by older persons in the community. J. Am. Geriatr. Soc. 1995, 43, 1214-1221. [CrossRef] [PubMed]

39. Kline, R.B. Exploratory and confirmatory factor analysis. In Applied Quantitative Analysis in the Social Sciences; Petscher, Y., Schatsschneider, C., Eds.; Routledge: New York, NY, USA, 2013; Chapter 6, pp. 171-207.

40. Holgado-Tello, F.P.; Chacón-Moscoso, S.; Barbero-García, I.; Vila-Abad, E. Polychoric versus Pearson correlations in exploratory and confirmatory factor analysis of ordinal variables. Qual. Quant. 2008, 44, 153. [CrossRef]

41. Kline, R. Principles and Practice of Structural Equation Modeling, 4th ed.; The Guilford Press: London, UK, 2015.

42. Tabachnick, B.G.; Fidell, L.S. Using multivariate statistics, 5th ed.; Allyn \& Bacon: Boston, MA, USA, 2007.

43. Yong, A.E.; Pearce, S. A Beginner's Guide to Factor Analysis: Focusing on Exploratory Factor Analysis. Tutor. Quant. Methods Psychol. 2013, 9, 79-94. [CrossRef]

44. Krippendorff, K. Computing Krippendorff's Alpha-Reliability. 2011. Available online: http://repository.upenn.edu/asc_papers/ 43 (accessed on 20 July 2021).

45. De Swert, K.; Calculating Inter-Coder Reliability in Media Content Analysis Using Krippendorff's Alpha. Working Paper. 2012. Available online: http:/ / www.polcomm.org/wp-content/uploads/ICR01022012.pdf (accessed on 20 July 2021).

46. van Hateren, K.J.; Alkhalaf, A.; Kleefstra, N.; Groenier, K.H.; de Jong, P.E.; de Zeeuw, D.; Gans, R.O.; Struck, J.; Bilo, H.J.; Gansevoort, R.T.; et al. Comparison of midregional pro-A-type natriuretic peptide and the N-terminal pro-B-type natriuretic peptide for predicting mortality and cardiovascular events. Clin. Chem. 2012, 58, 293-297. [CrossRef]

47. Campbell, D.T.; Fiske, D.W. Convergent and discriminant validation by the multitrait-multimethod matrix. Psychol. Bull. 1959, 56, 81-105. [CrossRef]

48. Hubley, A.M. Discriminant Validity. In Encyclopedia of Quality of Life and Well-Being Research; Michalos, A.C., Ed.; Springer Netherlands: Dordrecht, The Netherlands, 2014; pp. 1664-1667.

49. Henseler, J.; Ringle, C.M.; Sarstedt, M. A new criterion for assessing discriminant validity in variance-based structural equation modeling. J. Acad. Mark. Sci. 2015, 43, 115-135. [CrossRef]

50. Gefen, D.; Straub, D.; Boudreau, M.-C. Structural equation modeling and regression: Guidelines for research practice. Commun. AIS 2000, 4, 1-78. [CrossRef]

51. Herdman, M.; Gudex, C.; Lloyd, A.; Janssen, M.; Kind, P.; Parkin, D.; Bonsel, G.; Badia, X. Development and preliminary testing of the new five-level version of EQ-5D (EQ-5D-5L). Qual. Life Res. 2011, 20, 1727-1736. [CrossRef]

52. Lu, Y.; Fang, J. Advanced Medical Statistics; World Scientific Publishing, Co., Pte. Ltd.: Singapore, 2003.

53. Coast, J.; Peters, T.; Natarajan, L.; Sproston, K.; Flynn, T. An assessment of the construct validity of the descriptive system for the ICECAP capability measure for older people. Qual. Life Res. 2008, 17, 967. [CrossRef] 
54. Keeley, T.; Coast, J.; Nicholls, E.; Foster, N.E.; Jowett, S.; Al-Janabi, H. An analysis of the complementarity of ICECAP-A and EQ-5D-3 L in an adult population of patients with knee pain. Health Qual. Life Outcomes 2016, 14, 36. [CrossRef]

55. Kaambwa, B.; Gill, L.; McCaffrey, N.; Lancsar, E.; Cameron, I.D.; Crotty, M.; Gray, L.; Ratcliffe, J. An empirical comparison of the OPQoL-Brief, EQ-5D-3 L and ASCOT in a community dwelling population of older people. Health Qual. Life Outcomes 2015, 13, 164. [CrossRef]

56. Kaambwa, B.; Mpundu-Kaambwa, C.; Adams, R.; Appleton, S.; Martin, S.; Wittert, G. Suitability of the Epworth Sleepiness Scale (ESS) for Economic Evaluation: An Assessment of Its Convergent and Discriminant Validity. Behav. Sleep Med. 2018, 16, 448-470. [CrossRef] [PubMed]

57. Kaambwa, B.; Ratcliffe, J. Predicting EuroQoL 5 dimensions 5 levels (EQ-5D-5L) utilities from Older People's Quality of Life brief questionnaire (OPQoL-brief) scores. Patient Patient-Cent. Outcome Res. 2018, 11, 39-54. [CrossRef] [PubMed]

58. Chren, M.M.; Lasek, R.J.; Quinn, L.M.; Covinsky, K.E. Convergent and discriminant validity of a generic and a disease-specific instrument to measure quality of life in patients with skin disease. J. Investig. Dermatol. 1997, 108, 103-107. [CrossRef] [PubMed]

59. Guyatt, G.H.; Deyo, R.A.; Charlson, M.; Levine, M.N.; Mitchell, A. Responsiveness and validity in health status measurement: A clarification. J. Clin. Epidemiol. 1989, 42, 403-408. [CrossRef]

60. Drummond, M.F.; Sculpher, M.; O’Brien, B.; Stoddart, G.L.; Torrance, G.W. Methods for the Economic Evaluation of Health Care Programmes; Oxford University Press: Oxford, UK, 2005.

61. Coast, J.; Flynn, T.N.; Natarajan, L.; Sproston, K.; Lewis, J.; Louviere, J.J.; Peters, T.J. Valuing the ICECAP capability index for older people. Soc. Sci. Med. 2008, 67, 874-882. [CrossRef] [PubMed]

62. Coast, J.; Smith, R.; Lorgelly, P. Should the capability approach be applied in health economics? Health Econ. 2008, 17, 667-670. [CrossRef] [PubMed] 